\title{
The influence of surgical correction on white matter microstructural integrity in rabbits with familial coronal suture craniosynostosis
}

\author{
Christopher M. Bonfield, MD, ${ }^{1}$ Lesley M. Foley, BSc, ${ }^{2}$ Shinjini Kundu, MS, ${ }^{3}$ \\ Wendy Fellows-Mayle, PhD, ${ }^{1}$ T. Kevin Hitchens, PhD, ${ }^{2-4}$ Gustavo K. Rohde, PhD, ${ }^{3}$ \\ Ramesh Grandhi, MD, ${ }^{1}$ and Mark P. Mooney, $\mathrm{PhD}^{5}$
}

\begin{abstract}
${ }^{1}$ Department of Neurological Surgery, University of Pittsburgh Medical Center; ${ }^{2}$ Pittsburgh NMR Center for Biomedical Research and Departments of ${ }^{3}$ Biomedical Engineering and ${ }^{4}$ Biological Science, Carnegie Mellon University; and ${ }^{5}$ Departments of Oral Biology, Anthropology, Plastic Surgery, Orthodontics, and Communication Science and Disorders, University of Pittsburgh, Pittsburgh, Pennsylvania
\end{abstract}

OBJECT Craniosynostosis is a condition in which one or more of the calvarial sutures fuses prematurely. In addition to the cosmetic ramifications attributable to premature suture fusion, aberrations in neurophysiological parameters are seen, which may result in more significant damage. This work examines the microstructural integrity of white matter, using diffusion tensor imaging (DTI) in a homogeneous strain of rabbits with simple, familial coronal suture synostosis before and after surgical correction.

METHODS After diagnosis, rabbits were assigned to different groups: wild-type (WT), rabbits with early-onset complete fusion of the coronal suture (BC), and rabbits that had undergone surgical correction with suturectomy (BC-SU) at 10 days of age. Fixed rabbit heads were imaged at 12, 25, or 42 days of life using a 4.7-T, 40-cm bore Avance scanner with a 7.2-cm radiofrequency coil. For DTI, a 3D spin echo sequence was used with a diffusion gradient $\left(b=2000 \mathrm{sec} / \mathrm{mm}^{2}\right)$ applied in 6 directions.

RESULTS As age increased from 12 to 42 days, the DTI differences between WT and BC groups became more pronounced ( $p<0.05,1$-way ANOVA), especially in the corpus callosum, cingulum, and fimbriae. Suturectomy resulted in rabbits with no significant differences compared with WT animals, as assessed by DTI of white matter tracts. Also, it was possible to predict to which group an animal belonged (WT, BC, and BC-SU) with high accuracy based on imaging data alone using a linear support vector machine classifier. The ability to predict to which group the animal belonged improved as the age of the animal increased ( $71 \%$ accurate at 12 days and $100 \%$ accurate at 42 days).

CONCLUSIONS Craniosynostosis results in characteristic changes of major white matter tracts, with differences becoming more apparent as the age of the rabbits increases. Early suturectomy (at 10 days of life) appears to mitigate these differences.

http://thejns.org/doi/abs/10.3171/2015.2.FOCUS14849

KEY WORDS craniosynostosis; white matter; diffusion tensor imaging; fractional anisotropy; rabbit

$\mathrm{C}$ RANIOSYNOSTOSIS is a condition in which one or more of the calvarial sutures fuses prematurely. The overall incidence of craniosynostosis is estimated to be 1 out of 2500 live births. Most commonly, craniosynostosis is considered to be idiopathic and not associated with a genetic syndrome (Crouzon or Apert), a metabolic disease (Rickets or hyperthyroidism), or secondary to another process (shunted hydrocephalus). Craniosynostosis of the coronal sutures makes up approximately $25 \%$ of cases..$^{34}$

Children with the condition are commonly recognized by their distinct and abnormal head shape, which is deter-

ABBREVIATIONS $A D=$ axial diffusivity; $A D C=$ apparent diffusion coefficient; $D T I=$ diffusion tensor imaging; $F A=$ fractional anisotropy; ICP = intracranial pressure; $R D=$ radial diffusivity; $\mathrm{ROI}$ = region of interest; $\mathrm{SVM}=$ support vector machine.

SUBMITTED December 30, 2014. ACCEPTED February 12, 2015. INCLUDE WHEN CITING DOI: 10.3171/2015.2.FOCUS14849.

DISCLOSURE The authors report no conflict of interest concerning the materials or methods used in this study or the findings specified in this paper. This work was funded by the Posvar Hall Animal Care Facility, Department of Anthropology, University of Pittsburgh and NIH P41 EB001977. 
mined by which suture has prematurely closed. Virchow's law states that growth of the skull is typically restricted perpendicular to the fused suture and enhanced parallel to it. ${ }^{12}$ In some cases, the restricted skull may not provide enough space for the growing brain, resulting in clinical manifestations of increased intracranial pressure (ICP), such as visual impairment, headaches, or an impairment of mental development with a significant reduction in IQ. ${ }^{17}$ Studies in humans have shown that children with untreated craniosynostosis demonstrate delays in cognitive and psychomotor development. ${ }^{20,29}$ The prevalence of elevated ICP has been estimated to be as high as $20 \%$ in singlesuture synostosis ${ }^{36}$ and up to $60 \%$ in multisuture synostosis. ${ }^{31}$ If left uncorrected, the resulting deficits can be permanent and functionally devastating. Craniosynostosis treatment therefore has 2 aims: to restore a more normal head shape and to mitigate the risk posed by elevated ICP. Surgical correction is often performed in the 1st year of life, which leads to excellent cosmetic results and allows for unrestricted brain growth.

In addition to the cosmetic ramifications attributable to premature suture fusion, aberrations in neurophysiological parameters are seen, which may result in secondary brain injury. Along with increased ICP, $, 13,14,18,22,28$ abnormal cerebral blood flow ${ }^{10,11,32}$ contributes to potential white matter injury in craniosynostosis. Such damage manifests as structural and physiological impairments in cortical connectivity. Conventional MRI is able to detect the structural changes noninvasively, but only in a qualitative fashion and only after potentially irreversible damage has been done.

Diffusion tensor imaging (DTI), widely used to investigate tissue pathology and morphology, is based on characterizing the anisotropic diffusion of water to probe tissue microstructure. In the central nervous system, DTI has the ability to detect the direction of white matter fiber tracts and map neuronal connectivity. Quantitative diffusion information, such as fractional anisotropy (FA), can also be used to assess various neurodegenerative disorders involving white matter injury. Deviation, disruption, and edema of white matter tracts result in alterations of the FA and other parameters. ${ }^{37}$ Importantly, FA also correlates with neurocognitive function. ${ }^{4}$ DTI may likely be more sensitive than conventional structural MRI to white matter aberrations. Although DTI is a useful tool for probing brain pathophysiology, the literature is sparse regarding changes in DTI-based parameters in the developing brain with craniosynostosis, which predispose to chronic (often occult) ICP elevations.

The present study was undertaken to use DTI to study the age-related microstructural integrity of white matter in a homogeneous strain of rabbits with simple, familial coronal suture synostosis before and after surgical correction and to compare these values with age-matched wildtype control rabbits. This model allows the investigation of white matter in untreated and treated craniosynostosis from the early onset until a time when brain growth is complete. We investigated the hypothesis that aberrations in white matter integrity and functional connectivity exist in craniosynostosis and that surgical repair can result in normalization of these abnormalities.

\section{Methods}

\section{Animal Model}

This study used a breeding colony of New Zealand white rabbits with naturally occurring coronal suture synostosis. ${ }^{13,14,22,25,27,28}$ All rabbits were born and maintained in the vivarium at the Department of Anthropology, University of Pittsburgh, and housed in stainless steel cages with access to food and water ad libitum. Rabbits were housed with mothers and littermates up to the time of the experiment. Approval by the University of Pittsburgh Institutional Animal Care and Use Committee was obtained.

Synostotic rabbits were initially diagnosed at 10 days of age using previously described criteria. ${ }^{13,14,25,27,28}$ Briefly, coronal suture morphology was assessed, and the degree of coronal suture mobility was ascertained. Rabbits with dysmorphic but patent coronal sutures and limited mobility were diagnosed with delayed-onset synostosis and were omitted from the study. Rabbits with bilaterally fused coronal sutures with no mobility were diagnosed with earlyonset coronal suture synostosis $(\mathrm{BC})$ and were included in the study (Fig. 1).

Removal of the coronal suture (BC-SU) occurred immediately after diagnosis of synostosis in a subset of the animals. The coronal suture was removed by drilling 2 $\mathrm{mm}$ anterior to and $2 \mathrm{~mm}$ posterior to the suture for the length of the affected suture. A 4-mm $\times$ approximately 20-mm piece of the skull was removed (Fig. 2). The skin of the head was sutured, and the rabbit was monitored during recovery. Rabbits were given Baytril at a dose of 2 $\mathrm{mg} / \mathrm{kg}$ twice a day subcutaneously and buprenorphine at a dose of $0.02 \mathrm{mg} / \mathrm{kg}$ subcutaneously immediately after surgery and for 2 days postoperatively. The scalp incision was monitored daily, and the sutures were removed at 20 days of age. At specific time points, rabbits were killed, and the heads were fixed with paraformaldehyde.

Rabbits were randomly assigned into the following experimental groups: wild-type control rabbits (WT) at or near 12 days of age $(n=5)$; $\mathrm{BC}$ rabbits at or near 12 days of age $(n=4)$; BC-SU rabbits at or near 12 days of age $(n=$ 5); WT rabbits at or near 25 days of age $(n=4)$; $B C$ rabbits at or near 25 days of age $(n=5)$; BC-SU rabbits at or near 25 days of age $(n=5)$; WT rabbits at or near 42 days of age $(n=5)$; BC rabbits at or near 42 days of age $(n=4)$; and BC-SU rabbits at or near 42 days of age $(n=5)$.

\section{MRI Protocol}

MRI studies were performed using a 4.7-T, 40-cm bore Avance-AV system (Bruker), equipped with a 12-cm-diameter shielded gradient insert and a 72-mm-volume radiofrequency coil. The DTI experiments were performed on the fixed heads using a 3D spin echo diffusion-weighted sequence with a diffusion gradient time $(\delta)$ of $8 \mathrm{msec}$ and a delay between diffusion gradients $(\Delta)$ of $16 \mathrm{msec}$. Images were acquired at TR $1200 \mathrm{msec}$, TE $32 \mathrm{msec}$ with a $256 \times 192 \times 192$ matrix, and a field of view of $51.2 \times 51.2$ $\times 51.2 \mathrm{~mm}$. Six noncollinear diffusion directions were collected with a b-value of $2000 \mathrm{~s} / \mathrm{mm}^{2}$ and one with no diffusion weighting.

\section{Data Analysis}

Images were processed using ParaVision (version 5.1, 


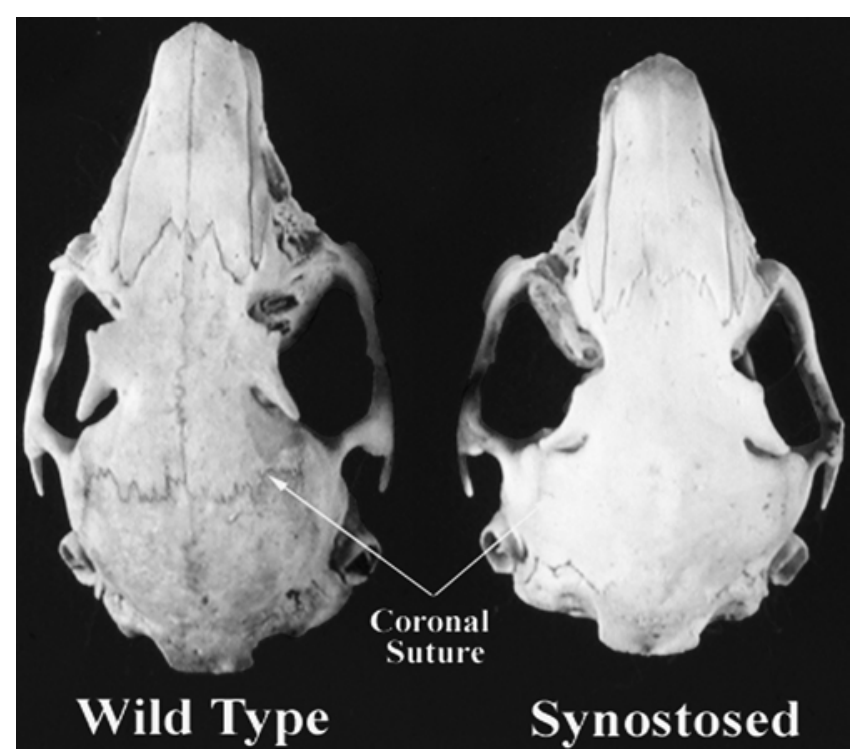

FIG. 1. Cleaned and dried skulls from a wild-type rabbit (left) and a rabbit with uncorrected coronal suture synostosis (right) at 25 days of age. Note the brachycephaly in the skull with uncorrected coronal suture synostosis.

Bruker Biospin), and DTI data were analyzed using DSI studio (http://dsi-studio.labsolver.org/) for tractography and quantitative diffusion parameters: apparent diffusion coefficient (ADC), FA, axial diffusivity (AD), and radial diffusivity (RD). For each subject, a 3D region of interest (ROI) was drawn within each hemisphere for the anterior commissure, corpus callosum, cingulum, fimbriae, and internal capsule. ROIs were drawn by a single observer and were assigned using a rabbit brain atlas. ${ }^{33}$ For the $\mathrm{BC}$ and BC-SU groups, deviations from normal anatomy did not impede ROI assignment. For consistency between subjects, several image contrast mechanisms $\left(\mathrm{T}_{2}\right.$-weighted image, FA map, ADC map, and diffusion tensor directionally encoded color map) were used to define the boundaries for each ROI.

\section{Statistical Analysis}

Average FA, ADC, AD, and RD values were computed for each anatomical region per animal and overall within each group. Values are expressed as means \pm SD. DTI parameters were compared among the animals belonging to each group and age. Significant differences were assessed using 1-way ANOVA with the aid of MATLAB software (MathWorks). Differences were considered significant at a level of $\mathrm{p}<0.05$.

Predictive studies examining whether DTI parameters can predict group membership at each age were performed using a linear support vector machine (SVM) classifier. If the set of DTI parameters for each animal are thought to represent a point in a multidimensional space, then 1 point in the space represents each animal. A linear SVM classifier seeks to find a hyperplane in the multidimensional space that draws a linear boundary between the points in each class. Individual classification was performed using a one-vs-one linear SVM with fixed parameter c = 1 utiliz-

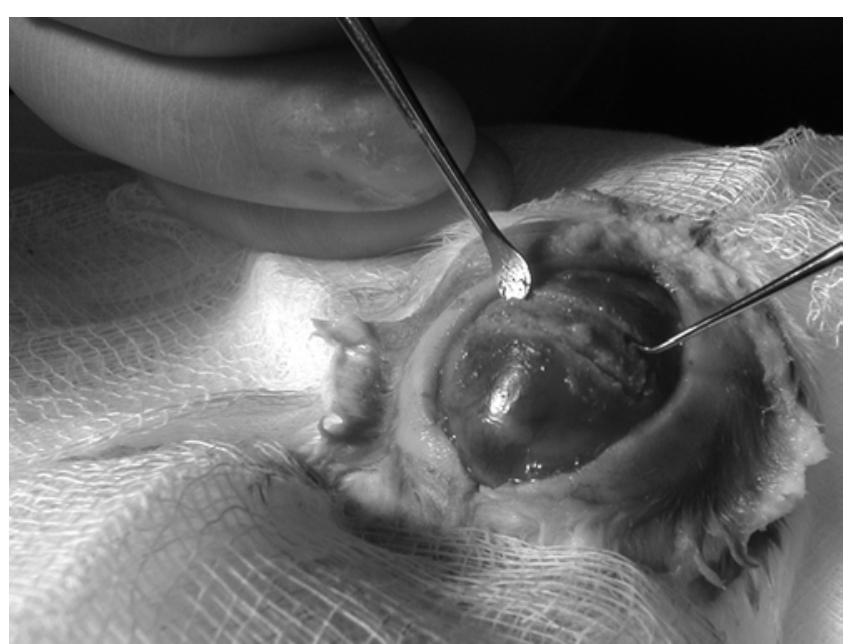

FIG. 2. Intraoperative photograph illustrating the coronal suturectomy.

ing the LIBSVM package in MATLAB (http://www.csie. ntu.edu.tw/ cjlin/libsvm/). Classification accuracy was determined by 5-fold cross-validation. Statistical significance of the SVM classifier was determined by permutation testing (200 tests).

\section{Results}

\section{Tractography}

Representative images of the white matter fiber tracts from WT, BC, and BC-SU rabbits at 42 days of age are shown in Fig. 3. BC rabbits appear to have fewer coherent fibers than WT rabbits, particularly in the corpus callosum and cingulum, which is somewhat restored after surgical correction in the BC-SU rabbits.

\section{Fractional Anisotropy}

Mean FA values for each group for the corpus callosum, cingulum, and fimbriae are shown in Fig. 4. No significant difference in mean FA was found for the anterior commissure and internal capsule; therefore, plots are not shown in Fig. 4 for these ROIs. Mean FA increased with age in the corpus callosum, cingulum, and fimbriae, and within each age group, mean FA values for BC rabbits were significantly lower than WT animals and BC-SU rabbits ( $p<0.01$, except for the corpus callosum at 25 days old $\mathrm{p}<0.05$; Fig. 4). Suturectomy returned the FA values to level of the WT rabbits.

\section{Apparent Diffusion Coefficient}

Figure 5 shows the mean ADC values for each age group and for the 3 tracts that displayed any differences between the WT, BC, and BC-SU groups (the corpus callosum, cingulum, and fimbriae). A significant increase in $\mathrm{ADC}$ was observed in the cingulum and corpus callosum of BC rabbits versus WT and BC-SU for both the 25- and 42 -day-old age groups $(\mathrm{p}<0.01)$. There were no differences seen in any of the 12-day-old rabbit white matter tracts or in the fimbriae of the 25- and 42-day-old animals. Again, there were no differences observed between WT and BC-SU animals. 

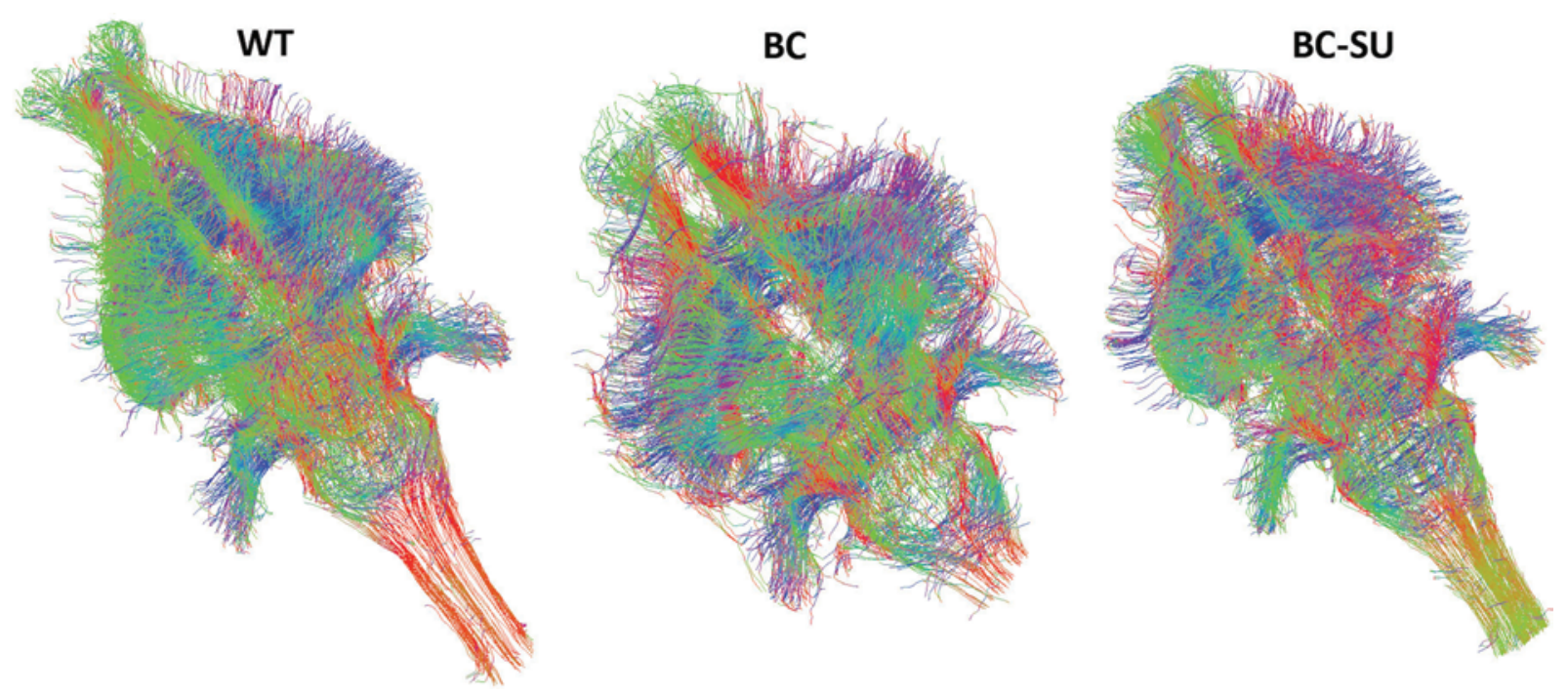

FIG. 3. Representative color tractography from a 42-day-old wild-type rabbit (WT), bilateral complete craniosynostotic rabbit $(B C)$, and an animal that has had corrective surgery (BC-SU). Data are from a single representative animal in each group. Fiber directionality can be seen by the different colors: blue (left/right), green (rostral/caudal), and red (dorsal/ventral). Differences can be observed between WT and BC and similarities between WT and BC-SU rabbits.

\section{Radial and Axial Diffusivity}

RD values decreased with increasing age (Fig. 6). Significant differences were again only seen in the 25 - and 42-day-old rabbits. RD was significantly increased in the corpus callosum, cingulum, and fimbriae of BC animals when compared with WT and BC-SU rabbits. The 12-dayold rabbits showed no significant differences in any of the ROIs studied.

$\mathrm{AD}$ was also compared between groups, but there were no significant differences seen between the WT, BC, and BC-SU rabbits for each age group and all ROIs.

\section{Individual Classification}

Blind prediction of each animal into WT, BC, and BCSU using the DTI data alone was performed using a linear SVM classifier. We were able to reliably identify animal categories with increasing accuracy as the number of days after the surgery increased (64\% at 12 days and $87 \%$ at 42 days; Table 1). Classification accuracy increased when only the DTI data from significant regions (corpus callosum, cingulum, and fimbriae) were analyzed (71\% at 12 days and $100 \%$ at 42 days; Table 2).

It was not possible, however, to reliably identify WT
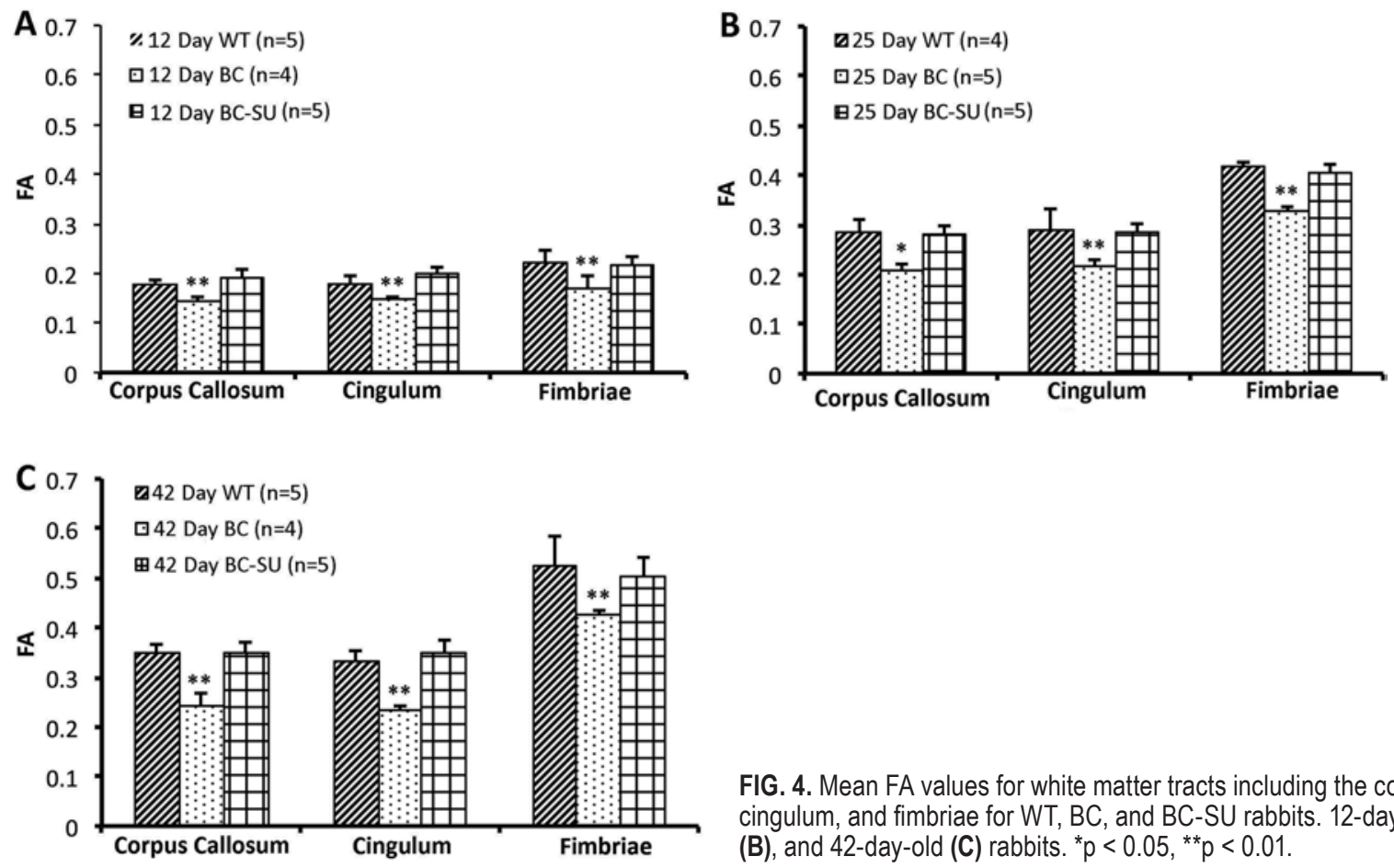

FIG. 4. Mean FA values for white matter tracts including the corpus callosum, cingulum, and fimbriae for WT, BC, and BC-SU rabbits. 12-day-old (A), 25-day-old (B), and 42-day-old (C) rabbits. ${ }^{*} p<0.05,{ }^{* *} p<0.01$. 

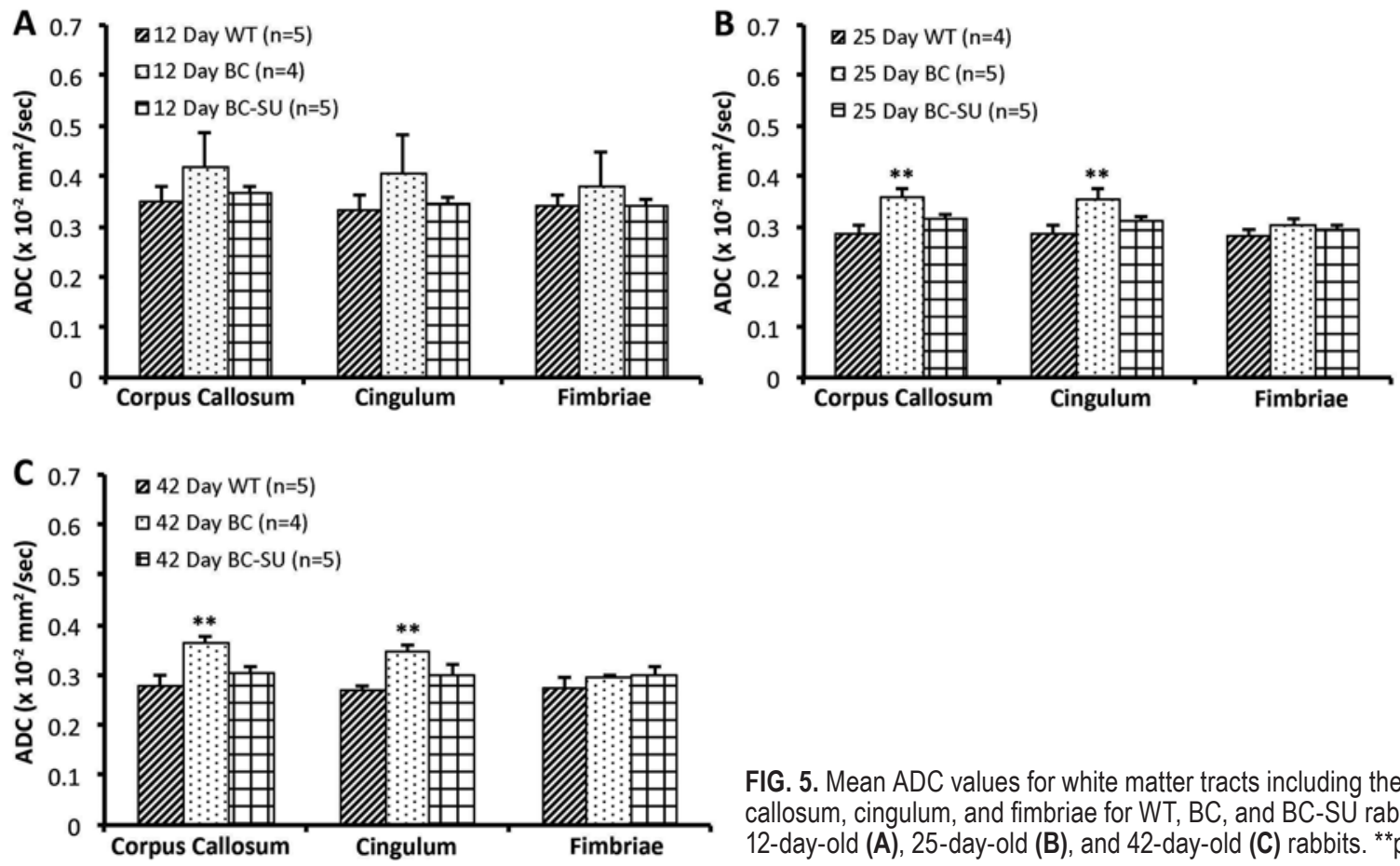

FIG. 5. Mean $A D C$ values for white matter tracts including the corpus callosum, cingulum, and fimbriae for WT, BC, and BC-SU rabbits. 12-day-old (A), 25-day-old (B), and 42-day-old (C) rabbits. ${ }^{* *} p<0.01$.

versus $\mathrm{BC} / \mathrm{BC}-\mathrm{SU}$ animals even as more days elapsed following surgeries (Table 3), but it was possible to distinguish between BC-SU versus BC animals (Table 4), as well as WT/BC-SU versus BC animals with high accuracy and reliability (Table 5).

The interrater agreement of the linear SVM classifier and known class labels for the WT, BC, and BC-SU groups was assessed using the Cohen's kappa statistic. Cohen's kappa corrects for agreement by chance, making it a more robust measure of agreement over simple percent agreement. A kappa value of 1 indicates perfect agreement, whereas a kappa value of 0 is agreement equivalent to chance.

\section{Discussion}

Using a well-established rabbit model of naturally occurring craniosynostosis, this study shows that water dif-
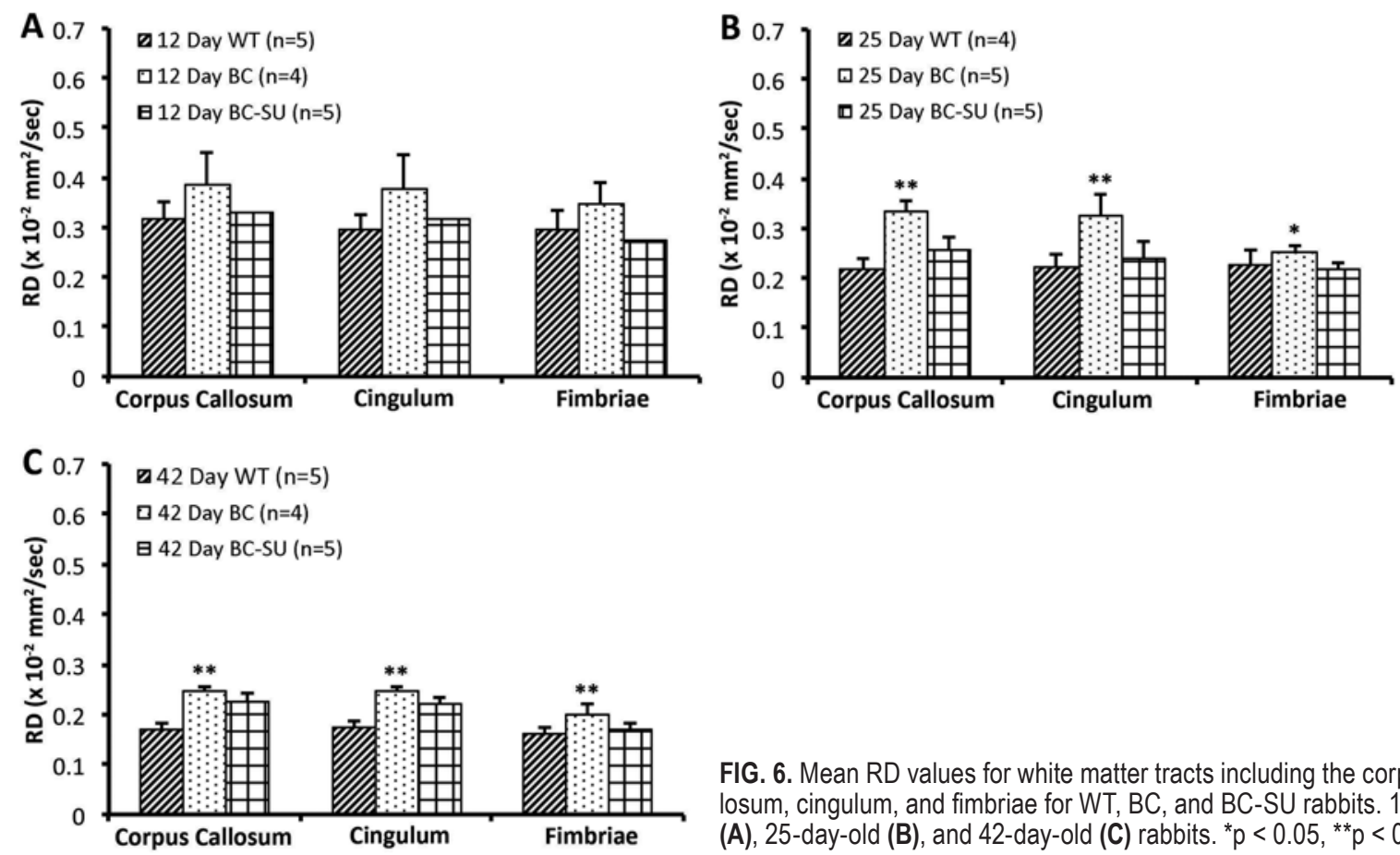

FIG. 6. Mean RD values for white matter tracts including the corpus callosum, cingulum, and fimbriae for WT, BC, and BC-SU rabbits. 12-day-old (A), 25-day-old (B), and 42-day-old (C) rabbits. ${ }^{*} p<0.05,{ }^{* *} p<0.01$. 
TABLE 1. Predicting group membership (WT, BC, and BC-SU) using all DTI parameters and regions

\begin{tabular}{cccc}
\hline Age & Correctly Classified & $p$ Value & Cohen's Kappa \\
\hline 12 days $(n=14)$ & $64 \%$ & $<0.005$ & 0.45 \\
\hline 25 days $(n=14)$ & $77 \%$ & $<0.005$ & 0.65 \\
\hline 42 days $(n=14)$ & $87 \%$ & $<0.005$ & 0.80 \\
\hline
\end{tabular}

fusion anisotropy in major white matter structures in the brain is significantly altered with uncorrected craniosynostosis. Furthermore, we demonstrated that early surgical correction mitigated adverse changes in the white matter tissue microstructure, with no statistically significant differences found in quantitative DTI parameters between surgically corrected and age-matched control animals. This study adds new evidence to the existing sequelae of craniosynostosis in the rabbit model, including decreased brain growth ${ }^{5}$ and intracranial volume, ${ }^{6}$ surface cortex blood flow anomalies ${ }^{16}$ and hyperactivity with early reflexive behavior in the early stages of life. ${ }^{21}$

It is known from past studies that simple coronal suturectomies were not able to completely normalize craniofacial growth, ${ }^{25}$ cranial base shape,$^{30}$ intracranial volume, ${ }^{6}$ or decrease $\mathrm{ICP}^{22}$ in rabbits from this colony. This was due in part to very rapid reossification of the suturectomy site by 42 days of age (Fig. 7). Adjuncts that prevent or delay postoperative reossification of the suturectomy site have all been shown to significantly improve and normalize these parameters. ${ }^{7,23,24,26}$ However, our results suggest that a completely normal head shape in the rabbits is not absolutely required to normalize DTI findings.

Our DTI data were obtained on fixed brains from rabbits at different ages and experimental groups to facilitate 3D DTI with high spatial resolution. Several studies have directly compared in vivo and ex vivo DTI measurements to show that water diffusion anisotropy is preserved in fixed tissues despite a 2- to 3-fold decrease in overall water diffusion. ${ }^{9,19,35,38}$ Temperature may partially explain a reduction in water diffusion rates since data are generally acquired at lower temperatures in fixed tissues (e.g., $\left.20^{\circ} \mathrm{C}\right)$ compared with normal physiological condition $\left(37^{\circ} \mathrm{C}\right)$; however, tissue fixation and its influences on DTI measurements can be complex and caution is always warranted when drawing conclusions about live tissue from ex vivo findings. For example, elapsed time between death and tissue fixation has been shown to have deleterious effects on DTI-derived parameters and tractography. ${ }^{8}$ Zhang et al. found no difference between live and ex vivo FA values from control mice; however, in mice with cuprizoneinduced demyelination, in vivo and ex vivo measured FA values were not in agreement. ${ }^{38}$ In our study, tissues were

TABLE 2. Predicting group membership (WT, BC, and BC-SU) using only significant parameters and regions

\begin{tabular}{cccc}
\hline Age & Correctly Classified & $p$ Value & Cohen's Kappa \\
\hline 12 days $(n=14)$ & $71 \%$ & $<0.005$ & 0.57 \\
\hline 25 days $(n=14)$ & $85 \%$ & $<0.005$ & 0.77 \\
\hline 42 days $(n=14)$ & $100 \%$ & $<0.005$ & 1 \\
\hline
\end{tabular}

TABLE 3. Predicting WT versus BC/BC-SU (all parameters)

\begin{tabular}{cccc}
\hline Age & Correctly Classified & $p$ Value & Cohen's Kappa \\
\hline 12 days $(n=14)$ & $64 \%$ & 0.38 & 0 \\
\hline 25 days $(n=14)$ & $69 \%$ & 0.79 & 0 \\
\hline 42 days $(n=14)$ & $87 \%$ & 0.005 & 0.67 \\
\hline
\end{tabular}

formalin fixed immediately postmortem to best preserve the tissue microstructure, and we expect the observed group differences to be valid in the absence of any confounding pathology.

In this study each animal was individually analyzed and we did not perform any rigid alignment or deformation-based morphometry to register animals to a common reference space. ROIs were drawn for each anatomical feature with guidance from a normal rabbit brain atlas. Every attempt was made to minimize the effect of morphological distortions in the brain due to craniosynostosis, by using a single observer and multiple image contrast mechanisms to define the ROI boundaries. The directionally encoded color map provided the best reference for white matter tract boundaries. It is possible that there was inclusion of unwanted voxels in the ROIs that could affect the results; however, the observed group differences should be valid since any methodological bias would be consistent across groups. Also, due to the small number of animals reviewed, some variation in response may be unique to the individual animal or may not be captured in using the group representative animal. Despite these limitations, this study is an example of an application of a noninvasive imaging modality that could provide insight into the anatomical etiology of the neurodevelopmental deficits seen in patients with craniosynostosis.

The utility of DTI-based biomarkers has been studied in other pediatric conditions. Studies have been published regarding DTI changes in children with increased ICP due to hydrocephalus. In these studies, decreased FA was seen in the periventricular white matter (e.g., corpus callosum) in patients with hydrocephalus compared with controls. Importantly, normalization was shown in these patients with successful hydrocephalus treatment. ${ }^{1,2}$

However, there is sparse literature regarding changes in DTI-based parameters in other conditions, such as craniosynostosis, which predispose to chronic (often occult) ICP elevations. Florisson et al. published a case series in which DTI revealed significant white matter integrity differences between syndromic children with craniosynostosis and healthy controls. ${ }^{15}$ The results of this study are not widely generalizable, as children with syndromic craniosynostosis constitute only a small fraction of craniosynostosis cases surgically treated at most craniofacial centers. In addition, children with syndromic craniosynostosis have

TABLE 4. Predicting BC versus BC-SU (all parameters)

\begin{tabular}{cccc}
\hline Age & Correctly Classified & p Value & Cohen's Kappa \\
\hline 12 days $(n=14)$ & $56 \%$ & 0.035 & 0 \\
\hline 25 days $(n=14)$ & $56 \%$ & 0.08 & 0 \\
\hline 42 days $(n=14)$ & $100 \%$ & 0.015 & 1 \\
\hline
\end{tabular}


TABLE 5. Predicting WT/BC-SU versus BC (all parameters)

\begin{tabular}{cccc}
\hline Age & Correctly Classified & $p$ Value & Cohen's Kappa \\
\hline 12 days $(n=14)$ & $86 \%$ & $<0.005$ & 0.59 \\
\hline 25 days $(n=14)$ & $100 \%$ & $<0.005$ & 1 \\
\hline 42 days $(n=14)$ & $100 \%$ & $<0.005$ & 1 \\
\hline
\end{tabular}

multisuture synostosis, and, as such, are at higher risk for ICP elevation than the typical patient with nonsyndromic single-suture synostosis. Importantly, no comparisons were made among individuals prior to and after surgery; as such, the influence of surgical correction on ameliorating aberrant white matter microarchitecture could not be determined. More recently, Beckett et al. investigated DTI data in adolescents who had previously undergone a cranial vault reconstruction for sagittal synostosis repair and compared them with data in controls. This report illustrated trends toward white matter alterations in all supratentorial lobes, although few findings reached statistical significance. This report also does not investigate preoperative imaging or younger children. ${ }^{3}$

The application of DTI to the craniofacial spectrum is still developing. We hope that our animal model study will serve as a background from which further human clinical studies will be formulated. Ultimately, DTI may allow for noninvasive determinations of white matter structural integrity and provide important data on functional connectivity in craniosynostosis. This study gives evidence that
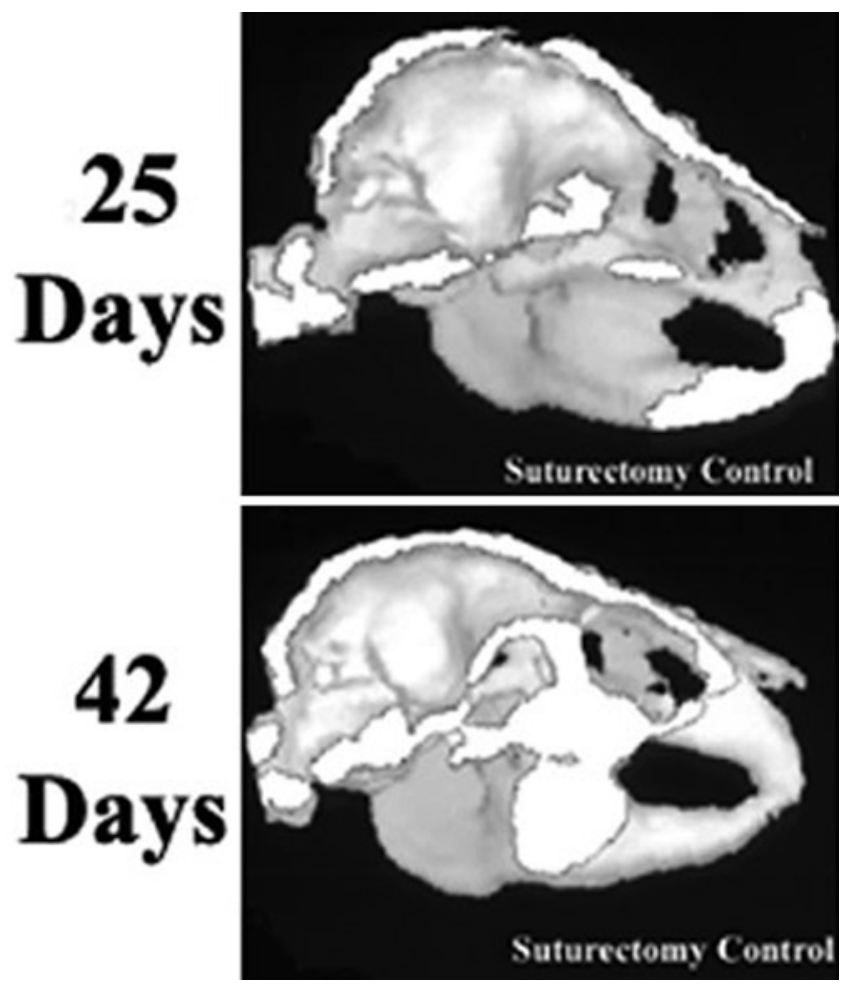

FIG. 7. Longitudinal lateral 3D CT reconstructions from a rabbit with coronal suturectomy at 25 and 42 days of age. Note the patent suturectomy site at 25 days and the reossified suturectomy site at 42 days of age and cranial vault brachycephaly. early craniosynostosis repair mitigates changes observed in the white matter structure of untreated animals. Further studies with the rabbit model will investigate if the timing of the surgery impacts the radiological findings. Whether this same pattern is seen in humans remains unknown. Ultimately, these imaging data will have to be coupled with neuropsychological testing to determine the ideal timing and technique for craniosynostosis repair for the optimal growth and development of the child.

\section{Conclusions}

Bilateral coronal craniosynostosis results in decreased water diffusion anisotropy of major white matter tracts, with differences becoming more apparent in older rabbits. This implies that craniosynostosis significantly affects the white matter tissue microstructure. These changes were mitigated in rabbits that underwent early suturectomy, providing evidence that suturectomy preserves white matter integrity compared with untreated craniosynostosis.

\section{References}

1. Air EL, Yuan W, Holland SK, Jones BV, Bierbrauer K, Altaye $\mathrm{M}$, et al: Longitudinal comparison of pre- and postoperative diffusion tensor imaging parameters in young children with hydrocephalus. J Neurosurg Pediatr 5:385-391, 2010

2. Assaf Y, Ben-Sira L, Constantini S, Chang LC, Beni-Adani L: Diffusion tensor imaging in hydrocephalus: initial experience. AJNR Am J Neuroradiol 27:1717-1724, 2006

3. Beckett JS, Brooks ED, Lacadie C, Vander Wyk B, Jou RJ, Steinbacher DM, et al: Altered brain connectivity in sagittal craniosynostosis. J Neurosurg Pediatr 13:690-698, 2014

4. Carmichael O, Lockhart S: The role of diffusion tensor imaging in the study of cognitive aging. Curr Top Behav Neurosci 11:289-320, 2012

5. Cooper GM, Mooney MP, Burrows AM, Smith TD, Dechant $\mathrm{J}$, Losken HW, et al: Brain growth rates in craniosynostotic rabbits. Cleft Palate Craniofac J 36:314-321, 1999

6. Cooper GM, Singhal VK, Barbano T, Wigginton W, Rabold $\mathrm{T}$, Losken HW, et al: Intracranial volume changes in craniosynostotic rabbits: effects of age and surgical correction. Plast Reconstr Surg 117:1886-1890, 2006

7. Cooper GM, Curry C, Barbano TE, Burrows AM, Vecchione L, Caccamese JF, et al: Noggin inhibits postoperative resynostosis in craniosynostotic rabbits. J Bone Miner Res 22:1046-1054, 2007

8. D'Arceuil H, de Crespigny A: The effects of brain tissue decomposition on diffusion tensor imaging and tractography. Neuroimage 36:64-68, 2007

9. D’Arceuil HE, Westmoreland S, de Crespigny AJ: An approach to high resolution diffusion tensor imaging in fixed primate brain. Neuroimage 35:553-565, 2007

10. David LR, Genecov DG, Camastra AA, Wilson JA, Argenta LC: Positron emission tomography studies confirm the need for early surgical intervention in patients with single-suture craniosynostosis. J Craniofac Surg 10:38-42, 1999

11. David LR, Wilson JA, Watson NE, Argenta LC: Cerebral perfusion defects secondary to simple craniosynostosis. J Craniofac Surg 7:177-185, 1996

12. Delashaw JB, Persing JA, Broaddus WC, Jane JA: Cranial vault growth in craniosynostosis. J Neurosurg 70:159-165, 1989

13. Fellows-Mayle WK, Mitchell R, Losken HW, Bradley J, Siegel MI, Mooney MP: Intracranial pressure changes in craniosynostotic rabbits. Plast Reconstr Surg 113:557-565, 2004

14. Fellows-Mayle WK, Mooney MP, Losken HW, Dechant J, 
Cooper GM, Burrows AM, et al: Age-related changes in intracranial pressure in rabbits with uncorrected familial coronal suture synostosis. Cleft Palate Craniofac J 37:370-378, 2000

15. Florisson JM, Dudink J, Koning IV, Hop WC, van Veelen ML, Mathijssen IM, et al: Assessment of white matter microstructural integrity in children with syndromic craniosynostosis: a diffusion-tensor imaging study. Radiology 261:534-541, 2011

16. Foley LM, Fellows-Mayle W, Hitchens TK, Losee JE, Barbano T, Siegel MI, et al: Age-related peridural hyperemia in craniosynostotic rabbits. Childs Nerv Syst 25:861-866, 2009

17. Gault DT, Renier D, Marchac D, Jones BM: Intracranial pressure and intracranial volume in children with craniosynostosis. Plast Reconstr Surg 90:377-381, 1992

18. Gosain AK, McCarthy JG, Wisoff JH: Morbidity associated with increased intracranial pressure in Apert and Pfeiffer syndromes: the need for long-term evaluation. Plast Reconstr Surg 97:292-301, 1996

19. Guilfoyle DN, Helpern JA, Lim KO: Diffusion tensor imaging in fixed brain tissue at 7.0 T. NMR Biomed 16:77-81, 2003

20. Kapp-Simon KA, Leroux B, Cunningham M, Speltz ML: Multisite study of infants with single-suture craniosynostosis: preliminary report of presurgery development. Cleft Palate Craniofac J 42:377-384, 2005

21. Mitchell RL, Barbano TE, Losken HW, Siegel MI, Mooney MP: Early neuromotor behavior in craniosynostotic rabbits. Cleft Palate Craniofac J 40:486-492, 2003

22. Mooney MP, Fellows-Mayle W, Losken HW, Dechant J, Burrows AM, Smith TD, et al: Increased intracranial pressure after coronal suturectomy in craniosynostotic rabbits. J Craniofac Surg 10:104-110, 1999

23. Mooney MP, Losken HW, Moursi AM, Bradley J, Azari K, Acarturk TO, et al: Anti-TGF- $\beta 2$ antibody therapy inhibits postoperative resynostosis in craniosynostotic rabbits. Plast Reconstr Surg 119:1200-1215, 2007

24. Mooney MP, Losken HW, Moursi AM, Shand JM, Cooper GM, Curry C, et al: Postoperative anti-Tgf- $\beta 2$ antibody therapy improves intracranial volume and craniofacial growth in craniosynostotic rabbits. J Craniofac Surg 18:336-349, 2007

25. Mooney MP, Losken HW, Siegel MI, Lalikos JF, Losken A, Burrows AM, et al: Development of a strain of rabbits with congenital simple nonsyndromic coronal suture synostosis. Part II: Somatic and craniofacial growth patterns. Cleft Palate Craniofac J 31:8-16, 1994

26. Mooney MP, Moursi AM, Opperman LA, Siegel MI: Cytokine therapy for craniosynostosis. Expert Opin Biol Ther 4:279-299, 2004

27. Mooney MP, Siegel MI, Burrows AM, Smith TD, Losken HW, Dechant J, et al: A rabbit model of human familial, nonsyndromic unicoronal suture synostosis. II. Intracranial contents, intracranial volume, and intracranial pressure. Childs Nerv Syst 14:247-255, 1998

28. Mooney MP, Siegel MI, Opperman LM: Animal models of craniosynostosis: experimental, congenital, and transgenic models, in Mooney MP, Siegel MI (eds): Understanding Craniofacial Anomalies: The Etiopathogenesis of Craniosynostosis and Facial Clefting. New York: Wiley-Liss, 2002, pp 209-250

29. Panchal J, Amirsheybani H, Gurwitch R, Cook V, Francel P, Neas B, et al: Neurodevelopment in children with single-suture craniosynostosis and plagiocephaly without synostosis. Plast Reconstr Surg 108:1492-1500, 2001

30. Putz DA, Smith TD, Burrows AM, Cooper GM, Dechant J, Losken $\mathrm{HW}$, et al: Cranial base changes following coronal suturectomy in craniosynostotic rabbits. Orthod Craniofac Res 5:90-103, 2002

31. Renier D, Lajeunie E, Arnaud E, Marchac D: Management of craniosynostoses. Childs Nerv Syst 16:645-658, 2000

32. Sainte-Rose C, LaCombe J, Pierre-Kahn A, Renier D, Hirsch JF: Intracranial venous sinus hypertension: cause or consequence of hydrocephalus in infants? J Neurosurg 60:727736, 1984

33. Shek JW, Wen GY, Wisniewski HM: Atlas of the Rabbit Brain and Spinal Cord. Basel, Switzerland: Karger, 1986

34. Slater BJ, Lenton KA, Kwan MD, Gupta DM, Wan DC, Longaker MT: Cranial sutures: a brief review. Plast Reconstr Surg 121:170e-178e, 2008

35. Sun SW, Neil JJ, Song SK: Relative indices of water diffusion anisotropy are equivalent in live and formalin-fixed mouse brains. Magn Reson Med 50:743-748, 2003

36. Tamburrini G, Caldarelli M, Massimi L, Santini P, Di Rocco $\mathrm{C}$ : Intracranial pressure monitoring in children with single suture and complex craniosynostosis: a review. Childs Nerv Syst 21:913-921, 2005

37. Witwer BP, Moftakhar R, Hasan KM, Deshmukh P, Haughton V, Field A, et al: Diffusion-tensor imaging of white matter tracts in patients with cerebral neoplasm. J Neurosurg 97:568-575, 2002

38. Zhang J, Jones MV, McMahon MT, Mori S, Calabresi PA: In vivo and ex vivo diffusion tensor imaging of cuprizoneinduced demyelination in the mouse corpus callosum. Magn Reson Med 67:750-759, 2012

\section{Author Contributions}

Conception and design: Bonfield, Foley, Fellows-Mayle, Grandhi, Mooney. Acquisition of data: Foley, Kundu, Fellows-Mayle, Hitchens, Rohde. Analysis and interpretation of data: Bonfield, Foley, Kundu, Fellows-Mayle, Hitchens, Rohde, Grandhi. Drafting the article: Bonfield, Foley, Kundu. Critically revising the article: all authors. Reviewed submitted version of manuscript: all authors. Approved the final version of the manuscript on behalf of all authors: Bonfield. Statistical analysis: Foley, Kundu, Hitchens, Rohde. Administrative/technical/material support: Mooney. Study supervision: Mooney.

\section{Correspondence}

Christopher M. Bonfield, Department of Neurological Surgery, University of Pittsburgh Medical Center, 200 Lothrop St., Ste. B-400, Pittsburgh, PA 15213. email: bonfieldcm@gmail.com. 